\title{
LAS COOPERATIVAS CENTENARIAS AGROALIMENTARIAS EN CATALUNYA: UN PATRIMONIO A ANALIZAR.
}

\author{
Manel Plana-Farran ${ }^{\mathrm{a} *}$, Yolanda Montegut $^{\mathrm{b}}$, Antonio Colom ${ }^{\mathrm{c}}$ \\ ${ }^{a}$ Universitat de Lleida Departament d'Empresa. Facultat de Dret, Economia $i$ Turisme (Lleida, \\ manel.plana@udl.cat) \\ ${ }^{b}$ Universitat de Lleida Departament d'Empresa. Facultat de Dret, Economia i Turisme (Lleida, \\ yolanda.montegut@udl.cat \\ ${ }^{c}$ Universitat de Lleida Departament d'Empresa. Facultat de Dret, Economia i Turisme (Lleida, \\ antonio_colom@hotmail.com)
}

\begin{abstract}
Las sociedades cooperativas son agentes económicos con una gran implantación en el ámbito agrario y constituyen uno de los instrumentos esenciales de desarrollo rural (Gallego, 2007). A esto se le puede añadir la consideración de las cooperativas como "una familia de familias" (Goel, 2013)

Según la Federació de Cooperatives Agràries de Catalunya, FCAC (2019) en Cataluña existen un total de 38 cooperativas agrarias que son ya centenarias y que continúan establecidas en el entorno donde fueron creadas (más del $20 \%$ son centenarias). La supervivencia y continuidad del cooperativismo se ha dado principalmente en el entorno rural que han contribuido a la vertebración del territorio y a la generación y distribución de riqueza. Las aportaciones que realizan estas organizaciones agrarias mediante la producción, la transformación y la comercialización de los productos agrarios, junto con los servicios a los socios y el arraigo a la comunidad en las que se encuentran ubicadas, las han convertido en imprescindibles.

El objetivo de este estudio es realizar un análisis descriptivo de estas cooperativas que han alcanzado los cien años de vida, analizando aquellos aspectos que son comunes, aportándonos información esencial sobre la pervivencia de estas organizaciones centenarias. El marco teórico de este análisis se basará en la teoría de los capitales de Bourdieu.
\end{abstract}

Palabras Clave: Cooperativas Agrarias, Continuidad, Supervivencia, Teoría de los Capitales.

\section{Introducción}

Las sociedades cooperativas son agentes económicos con una gran implantación en el ámbito agrario, constituyendo uno de los instrumentos esenciales del desarrollo rural (Gallego, 2007). Cataluña ha sido precursora del movimiento cooperativo en el estado español (Aymerich Cruells, J; 2005), convirtiéndose en un territorio en el que las entidades asociativas con contenido económico han tenido, históricamente, una presencia muy importante.

La supervivencia y la continuidad del cooperativismo ha tenido lugar, principalmente, en el entorno rural por medio de las cooperativas agrarias, contribuyendo a la vertebración del territorio, así como la generación y distribución de riqueza. La tarea que realizan las cooperativas agrarias mediante la producción, la transformación y la comercialización de los productos, junto con los servicios a los socios y el arraigo a la comunidad a la que se encuentran ubicadas han convertido en elementos fundamentales para su presencia a lo largo de todo nuestro país.

Uno de los rasgos que definen el medio rural es la centralidad del medio físico en las actividades productivas, la importancia que tiene en el entramado rural el sector primario y todo el conjunto de actividades conexas que se derivan de esta actividad principal. Es lo que se llama el efecto "tracción" de la actividad agraria hacia otros sectores que se desarrollan a partir de esta actividad inicial (industria transformadora, abonos, maquinaria agrícola ....)

La finalidad de este trabajo es averiguar primero y analizar después aquellos factores que se repiten respecto al comportamiento de las cooperativas que han alcanzado la cifra de los cien años desde su fundación y que continúan en funcionamiento. La supervivencia, como mínimo centenaria, y su continuidad se incorporan como un factor de éxito que aporta una serie de informaciones: Una salud económica y financiera que ha permitido esta continuidad, una aceptación social y una capacidad de representación socioeconómica en aquellos lugares donde se encuentran ubicadas las cooperativas centenarias y la adquisición de una capacidad de resiliencia y adaptación a las circunstancias del entorno y finalmente una capacidad de renovación y continuidad de todos los colectivos que forman parte de las cooperativas.

Según FCAC, Federació de Cooperatives Agràries de Catalunya, (2019) y según las propias investigaciones, en Cataluña hay un total de 38 cooperativas agrarias que son centenarias. 


\section{Cooperativismo y entorno}

La longevidad de cualquier organización es un factor de éxito representado por la pervivencia y la continuidad en el tiempo. En el caso que nos corresponde se quiere ir más allá de la mera descripción, haciendo un análisis más en profundidad para extraer las prácticas y los comportamientos de estas organizaciones que, a pesar de los cambios profundos que han existido en estos cien o más años de vida, continúan con su actividad.

Las cooperativas son en primer lugar y principalmente, organizaciones basadas en la agrupación de sus miembros (Jussila, Goel \& Tuominen, 2012), fundamentadas en las relaciones a largo "término" y en la repetición de las acciones de intercambio entre sus miembros para generar un beneficio colectivo que es superior a la suma de los "ímputs" que pueden ser aportados de forma individual. Estos intercambios mejoran la implicación colectiva entre los socios, pero a la vez también generan un conflicto en relación a la variedad de elecciones a tomar (Goel 2016). La estructuración de la toma de decisiones del colectivo y la autogestión así como los órganos de gobierno son fundamentales tanto en las decisiones como en la aceptación de las mismas.

Las cooperativas centenarias se encuentran principalmente en el sector agroalimentario, y es por ello que la investigación y el trabajo se ha ceñido en exclusiva al análisis las cooperativas agrarias.

Cataluña, como su entorno, ha visto como en los últimos períodos la industria agroalimentaria ha tenido que hacer frente a una serie de cambios en su propio funcionamiento y en las relaciones entre los actores que forman parte de la cadena agroalimentaria. Autores como Alsos et al. (2011) y Vik and McEwee (2011) argumentan que estos cambios tienen una afectación directa en las explotaciones agrarias, en la vida de las personas que se dedican a las explotaciones agrarias y en todos aquellos grupos y colectivos que se encuentran unidos y cooperan en este campo, entre elllos las cooperativas agrarias.

El sector agroalimentario es un sector altamente regulado y las reformas políticas en el ámbito europeo, estatal y catalán han llevado a una disminución de las ayudas al sector, afectando especialmente al sector primario. Los requerimientos de calidad y seguridad alimentaria cada vez son más altos a lo que se tiene que añadir un cambio en los gustos y demandas de los consumidores. La volatilidad de los mercados y la utilización de los productos agrarios como "comodities" más que como un elemento de abastecimiento de mercados y de seguridad alimentaria (Suess-Reyes et al. 2016), son otros aspectos a tener en cuenta. Un cambio en los valores sociales, un cambio tecnológico cada vez más creciente y las consecuencias del cambio climático son un reto para el sector agroalimentario y en especial por los productores y las asociaciones de productores como son las cooperativas. La reducción de la renta agraria (Cauces Revista, 2016) y un incremento de presión para responder a un cambio económico, social, político y tecnológico, obliga a las cooperativas agrarias a meterse en nuevas estrategias para asegurar la continuidad de las mismas.

\subsection{Las explotacions agrarias familiares, principales actores del cooperativisme agrario}

El 96\% de las explotaciones agrarias existentes en el ámbito de la EU28 son explotaciones de tipo familiar (EC 2016). Estos datos nos permiten introducir la tesis de Goel (2013) en la que argumenta que las cooperativas son una familia de familias. Hogeland (2015) utiliza la metáfora "las cooperativas son como familias" en un trabajo en el que analiza las diferentes respuestas que puede llegar a dar el cooperativismo agrario ante el escenario de incertidumbre; de hecho argumenta que "La industrialización de la agricultura del siglo XX y del XXI obligó al cooperativismo a dar una respuesta a un proceso que ni iniciaron, ni han dirigido". Algunos autores como Foreman and Whetten (2002) indican la militancia ideológica de la "ideología agraria". El movimiento cooperativo representa unos valores y una forma de vivir que imbuye el propio comportamiento de la organización y de los individuos que la conforman.

\section{Marco teórico}

La relación socio-cooperativa está impregnada de un contexto relacional, donde el concepto de capital social (Bourdieu, 1986) adquiere especial relevancia en el análisis de la misma. El capital social se ha utilizado para evaluar la calidad de las relaciones, incluyendo la confianza, las normas relacionales y las redes sociales como aspectos que pueden ayudar a mejorar la actividad de las relaciones (Spear, 2000).

El estudio de las cooperativas centenarias nos lleva a tener en cuenta aspectos también relacionados con la sociología y con la creencia de que el propio comportamiento de los colectivos se encuentra fundamentado en los orígenes sociales de las personas (Glover, 2008) y de las propias organizaciones creadas a partir de la unión y la cooperación de los actores; en este caso, principalmente agricultores y ganaderos en un contexto y en unas circunstancias determinadas. También nos dará la posibilidad de ampliar el análisis a los principales actores que han conformado las cooperativas, i.e las explotaciones agrarias familiares (Ilbery, 1983; Young et al. 1995). 


\section{Resultados}

El número de socios de las Cooperativas Centenarias nos indica lo siguiente: El 45\% tienen entre 0-99 socios; el 18\% entre 100-199 socios; el 13\%, entre 200-299 socios y el 24\%, más de 300 socios. Por lo tanto, la mayoría de las cooperativas centenarias, el $75 \%$, no superan los 300 socios.

En la mayoría de las Cooperativas Centenarias, el número de socios totales es muy superior al número de socios productores. Esto nos indica el envejecimiento de la población agraria y la falta de relevo generacional. Ahora bien, el socio, aun no siendo productor, continúa vinculado con la misma. Por otra parte, el $42 \%$ de las Cooperativas Centenarias forman parte de alguna entidad cooperativa de segundo grado. Cerca del $50 \%$ de las Cooperativas Centenarias no superan 1 M.€ de facturación y solamente 4 de las 38 facturan más de $9 \mathrm{M} €$. En lo referente a las exportaciones, el $60 \%$ de estas cooperativas no comercializan sus productos en el ámbito internacional, focalizando su actividad comercial en el entorno estatal.

Finalmente, se informa que el 55\%, tienen una sección de crédito como un servicio incorporado a los socios y a la comunidad en la que se encuentran ubicadas estas organizaciones. En relación a la prestación de servicios, el $65 \%$ de este tipo específico cooperativo, ofrece otros servicios y actividades a los socios, más allá de las de comercialización.

Gráfico 1. Descripción Cooperativas Centenarias.

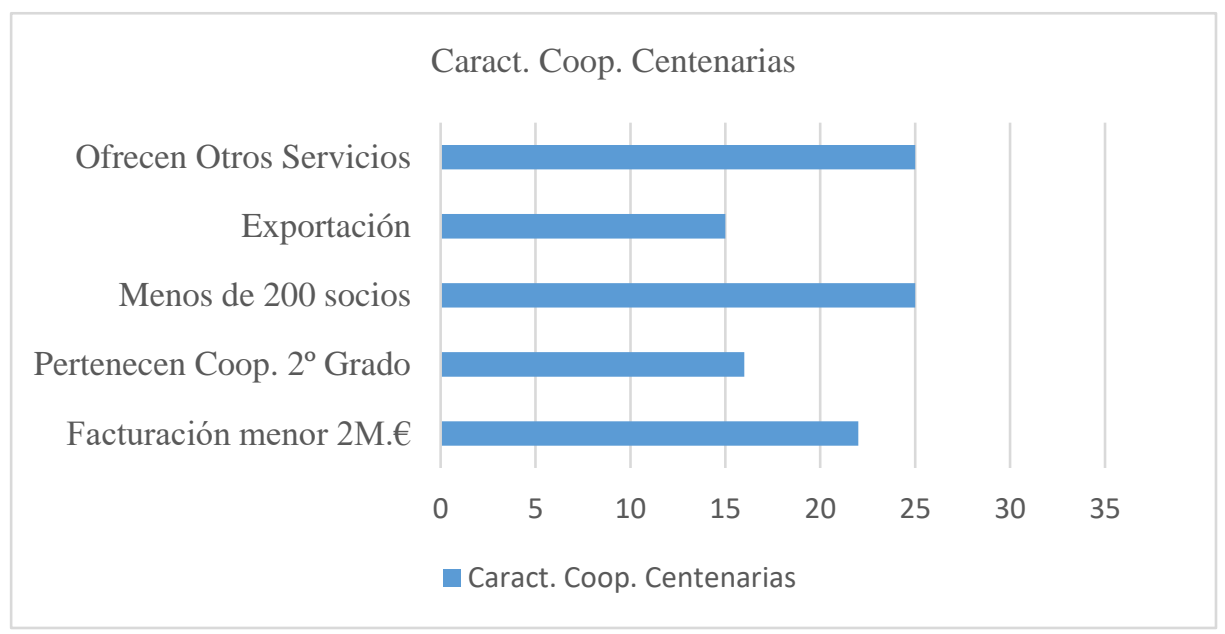

\section{Conclusiones}

Un porcentaje elevado de Cooperativas Agroalimentarias en Catalunya son centenarias (más de un 20\%). Esto indica un alto índice de supervivencia y continuidad; a su vez, los datos nos muestran la reducida dimensión de las mismas (el 75\% de las mismas no superan los 300 socios), y los bajos niveles de facturación (casi el 50\% no superan el 1 M.€).

Las Cooperativas centenarias son un elemento fundamental de anclaje de actividad agro-social; a su vez, la dimensión de las mismas, la falta de agrupación en organizaciones de $2^{\circ}$ grado y el nivel de facturación, nos indica una cierta debilidad en lo que se refiere a la continuidad de estas organizaciones y el consiguiente probable perjuicio para el entorno rural en el que se encuentran ubicadas en el caso que no exista un relevo generacional.

\section{Bibliografía.}

Alsos, GA and Carter, S. (2006). Multiple business ownership in the Norwegian farm sector: Resource transfer and performance consequences. Journal of Rural Studies, 22: 313-22.

Aymerich Cruells, J. (2005): "Las cooperativas y las colectivizaciones obreras en Cataluña como modelos de gestión colectiva. Proceso de regulación legal (1839-1939), Universitat de Barcelona-Tesi Doctoral

Bourdieu, P. (1986). "The forms of capital". In Handbook of Theory and Research for the Sociology of Education, Edited by: Richardson, J. G. New York: Greenwood.

Foreman, P. \& Whetten, D. (2002). Members' identification with multiple-identity organizations. Organizational Science, 13(6), 618-635

Gallego, L.P. (2007). Función de las cooperativas en la normativa de fomento del desarrollo rural. Revesco: Revista de estudios cooperativos, $n^{\circ}$ 92, págs.. 153-177 
Glover, J.L. (2008) Why do Dairy Farmers Continue to Farm? Can Bourdieu's Theory Aid Our Understandings and Suggest How Farmers Could Regain Some Control in their Industry?. Doctoral Thesis. Loughborough University

Goel, S., (2013). Relevance and potential of co-operative values and principles for family business research and practice. Journal of Co-operative Organization and Management 1 (2013) 41-46

Hogeland, J. A (2015): "Managing uncertainity and expections: The strategic response of U.S. agricultural cooperatives to agricultural industrialization", Journal of Co-operative Organization

Ilbery, B.W. \& R. Hornby (1983) Repertory Grids and Agricultural Decision-Making: A MidWarwickshire Case Study, Geografiska Annaler: Series B, Human Geography, 65:2, 77-84

Jusila, I., Goel, S., \& Tuominen, P. (2012). Governance of co-operative organizations: A social Exchange perspective. Business and Management Research, 1, 14-25

Spear, R. (2000): “The co-operative advantge”. Annals of Public and Cooperative Economics (71); pp. 507523

Suess-Reyes, J.; Fuetsch E. (2016); "The future of farming: A literature review on innovative, sustainable and succession-oriented strategies". Journal of Rural Studies 47; pp 117-140 